\title{
Photocatalytic Nanocomposite Polymer-TiO 2 Membranes for Pollutant Removal from Wastewater
}

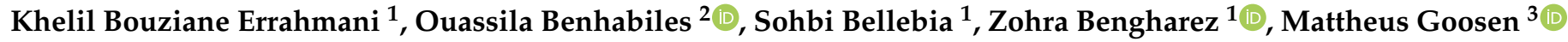 \\ and Hacene Mahmoudi ${ }^{4, *}$ \\ 1 Laboratory of Advanced Materials and Physicochemistry for Environment and Health, \\ Faculty of Exact Sciences, Djillali Liabes University Sidi Bel Abbes, P.O. Box 89, Sidi Bel Abbes 22000, Algeria; \\ be.kheli1@gmail.com (K.B.E.); bellebia_sohbi@yahoo.fr (S.B.); dzbengharez@yahoo.fr (Z.B.) \\ 2 Unité de Développement des Equipements Solaires, UDES/Centre de Développement des Energies \\ Renouvelables, CDER, Bou Ismail, Tipaza 42004, Algeria; benhabiles.ouassila@gmail.com \\ 3 Office of Research \& Graduate Studies, Alfaisal University, P.O. Box 50927, Riyadh 11533, Saudi Arabia; \\ mgoosen@alfaisal.edu \\ 4 Faculty of Technology, University Hassiba Benbouali of Chlef, Chlef 02000, Algeria \\ * Correspondence: h.mahmoudi@univ-chlef.dz; Tel.: +213-777170833
}

\section{check for} updates

Citation: Bouziane Errahmani, K.; Benhabiles, O.; Bellebia, S.; Bengharez, Z.; Goosen, M.; Mahmoudi, H. Photocatalytic Nanocomposite Polymer-TiO 2 Membranes for Pollutant Removal from Wastewater. Catalysts 2021, 11, 402. https://doi.org/10.3390/catal 11030402

Academic Editors: Gassan Hodaifa and Rafael Borja

Received: 8 February 2021

Accepted: 17 March 2021

Published: 23 March 2021

Publisher's Note: MDPI stays neutral with regard to jurisdictional claims in published maps and institutional affiliations.

Copyright: (c) 2021 by the authors. Licensee MDPI, Basel, Switzerland. This article is an open access article distributed under the terms and conditions of the Creative Commons Attribution (CC BY) license (https:// creativecommons.org/licenses/by/ $4.0 /)$.

\begin{abstract}
Photocatalytic $\mathrm{TiO}_{2}-\mathrm{PVDF} / \mathrm{PMMA}$ nano-composites flat sheet membranes were fabricated by phase inversion and then employed in a crossflow filtration pilot to remove model pollutants of various sizes and charge from aqueous solution. The dope solution contained a mixture of PVDF and PMMA as polymers, polyethylene glycol (PEG) and polyvinylpyrrolidone (PVP) as additives, triethyl phosphate (TEP) as green solvent and $\mathrm{TiO}_{2}$ as immobilized photo catalyst. After undergoing characterization tests such as SEM morphology thickness, porosity, contact angle and water permeability, the membranes were used to eliminate the model pollutants from synthetic aqueous solution. The impact of the operating conditions (i.e., $\mathrm{pH}$, pressure and initial pollutant concentration) and composition of the doping solution on the performance and photocatalytic and antifouling activity of the membranes was investigated. The results showed that Congo Red and Tartrazine despite their small size were rejected at $99 \%$ and $81 \%$, respectively, because of their negative charge, while Ciprofloxacin, which is larger than Tartrazine but of neutral charge, crossed the membrane. The permeability did not decrease with a decline in pollutant concentration but diminished when the pressure increased and was reduced by more than half for wastewater.
\end{abstract}

Keywords: wastewater treatment; photo catalytic micro ultra-filtration; $\mathrm{PVDF} / \mathrm{PMMA} / \mathrm{TiO}_{2}$ nano composite membranes; MWCO

\section{Introduction}

Efficient techniques for wastewater treatment are critical not only to limit the release of pollutants into the natural environment, but also to produce safe potable water for human consumption. Organic compound contaminants for example are found in the effluents from the textile, food, and pharmaceutical industries [1]. Furthermore, the water produced by conventional purification processes can still contain micropollutants such as pharmaceuticals, pesticides and chemicals which are harmful to the ecosystem and human health, especially for young children, infants, and pregnant women [2]. The incidence of a variety of recently recognized compounds of anthropogenic or natural origin in the marine environment has also turned out to be a worldwide environmental concern. These pollutants are mainly organic in nature and usually occur in trace concentrations in the range from parts per trillion (ppt or $\mathrm{ng} / \mathrm{L}$ ) to parts per billion (ppb or $\mu \mathrm{g} / \mathrm{L}$ ) $[1,3]$. There is thus an urgent need for developing efficient effluent treatment practices.

Advanced oxidation techniques for the treatment of water and wastewater have been the subject of several research projects aimed at the selection of materials such as 
semiconductors and their composites as well as optimal process treatment operating conditions [4-9]. Among the numerous photocatalysts assessed titanium dioxide $\left(\mathrm{TiO}_{2}\right)$ was found to be the best due to its ready availability and low cost [10]. The effectiveness of $\mathrm{TiO}_{2}$, as a heterogeneous catalyst for photo-degradation of aqueous pollutants and disinfection, was found to depend predominantly on the initial concentration of pollutants as well as on the light intensity on the $\mathrm{TiO}_{2}$ surface.

As well, membrane filtration technology has been extensively utilized not only in desalination but also in wastewater treatment, the food industry, pharmaceuticals manufacturing, and fermentation reactions [11,12]. Several researches on the application of membranes for wastewater treatment were investigated. For example, A.M. Khalil et al. [13] developed a cross-linked $\beta$-cyclodextrin nanofiber composite membrane for steroid hormone micropollutant removal. Similarly, L. Cseri et al. [14] suggest that nanofibrous polyimide membranes enhanced with ion exchange properties are promising candidates for the treatment of dye-laden textile wastewater.

As a real-world example of the application of nanocomposite materials, Ahdab and Rehman [15] studied brackish water desalination for greenhouses by employing monovalent selective electrodialysis reversal (MSED-R) for improving groundwater quality for irrigation. Experimentally determined membrane selectivities were used to evaluate the nutrient and fertilizer cost savings of MSED-R relative to Reverse Osmosis (RO).

For environmental remediation, A. Alammar et al. [16] prepared nanocomposite hydrogels based on sustainable cellulose acetate and demonstrated their robustness and practicality in continuous environmental remediation by using the hydrogels to treat contaminated groundwater from the Adyar River in India.

However, a major drawback of membrane processes is fouling. This phenomenon is due to the deposition of minerals, as well as colloidal and organic substances on the membrane surface $[10,17]$. The deposition process can be complex. Quantitative analysis for example has been done of membrane fouling mechanisms involved in microfiltration of humic acid-protein mixtures [17]. Clogging decreases the filtration flow, which considerably increases energy requirements, the rate at which membranes must be changed, the washing frequency and consequently the overall cost of the operation.

Furthermore, in the case of photocatalytic membranes which are a hybrid technology, as with all new processes, there are challenges that need to be overcome. Progress has been made for instance in photocatalytic membrane reactors (PMR) for water treatment. Such reactors exhibit enormous potential in the field of water treatment and in the cleansing of the environment [18-22]. In this photocatalysis-membrane system the benefits of two systems are combined [23].

A variety of studies have been reported on hybrid ultrafiltration/photocatalytic membranes for water treatment $[3,24-26]$. These include flat micro ultrafiltration membranes [24]. Among recent studies on photocatalytic membranes, Polyethersulfone (PES)/ sulfonated polysulfone (SPSf) $/ \mathrm{TiO}_{2}$ mixed matrix membranes (MMMs) were fabricated for oil-in-water emulsion separation. Results show that small concentrations of $\mathrm{TiO}_{2} \mathrm{NPs}$ can be used to successfully modify morphology and separation performance of membranes according to C. N. Matindi et al. [27]. Jie Yu et al. [28] report that membranes fabricated using a solvothermal-induced assembly of a 2D-2D reduced graphene oxide ( $\mathrm{rGO}$ )- $\mathrm{TiO}_{2}$ mesoporous material with a laminar structure have an impressive self-cleaning ability and thus exhibit great potential application in the field of membrane separation.

Polyvinylidene fluoride (PVDF) membranes have great potential since a negative charge on the surface of the membrane prevents the adhesion of bacteria, thus limiting biofouling $[23,25,26]$. Furthermore, PVDF is a highly crystalline linear polymer with chemical and mechanical thermal stability. In addition, PMMA (polymethyl methacrylate) is a polymer with a higher transparency index than the mineral glass allowing for enhanced penetration of light and thus improved photocatalytic activity [24]. However, according to Benhabiles et al. [20], membranes prepared using PMMA have a low mechanical resistance. 
It can be argued that owing to the strong compatibility of PVDF and PMMA, the combination of both polymers in a membrane may be employed to give enhanced overall properties such as improved mechanical resistance, hydrophilicity, processability, and ionic conductivity. Furthermore, membranes have recently been fabricated using triethyl phosphate (TEP) as the polymer solvent. Substituting hazardous solvents with TEP represents an attractive alternative for membrane fabrication. The solvent which has a high boiling point $\left(215^{\circ} \mathrm{C}\right)$ and has complete miscibility with water and alcohols, has been investigated by several authors $[20,29-31]$.

In the current study, the application of photocatalytic nanocomposite polymer- $\mathrm{TiO}_{2}$ membranes fabricated by phase inversion was assessed for pollutant removal from aqueous solutions including wastewater. $\mathrm{TiO}_{2}-\mathrm{PVDF} / \mathrm{PMMA}$ nano-composites flat sheet membranes were prepared by NIPS (Non-Solvent Induced Phase Separation). Scanning electron microscopy (SEM) was employed to characterize the surface and the cross-section morphology of the membranes. Pore size, pure water permeability (PWP), porosity, and contact angle measurements were also carried out. The fabricated membranes were assessed in a crossflow filtration cell on their effectiveness in removing pollutants with diverse molecular weights, shapes, and charges. Filtration tests for gram- and gram + bacterial suspensions were also performed. The final part of this study focused on membrane filtration performance including the effect of different operating conditions such as $\mathrm{pH}$, operating pressure, and initial pollutant concentration. Antifouling and antibiofouling properties were also investigated.

\section{Results and Discussion}

\subsection{Membrane Morphology}

Morphology plays a fundamental role in membrane behavior and filtration performance. Membrane permeability and selectivity are both affected by membrane morphology [32]. SEM analysis of the surface (top and bottom) and cross-section of the membranes indicated that the morphology of PVDF/PMMA nanocomposites is homogeneous and has a sponge-like symmetric formation (Figure 1).

The structure of the M1 membrane was homogeneous, with small pores of the same size distributed on the upper surface. The membrane showed a porous structure with interconnected pores and an absence of macro voids. This arrangement can be due to the higher polymer content in the M1 casting solution, which would have increased the viscosity [33]. It is generally recognized that a rise in solution viscosity strongly limits water passage through the polymer chains, thus hindering the formation of macro voids in the membrane. The presence of PVP and PEG additives in the dope solutions would also have contributed to the formation of membranes with a discontinuous cross-section structure. Furthermore, it can be argued that the presence of triethyl phosphate (TEP) as an alternative non-toxic solvent would have slowed down the phase separation rate, leading to a porous spongy membrane [34].

Membrane M2 was observed to contain visible macro voids according to the crosssection image (Figure 1). This structure can be induced by a lower polymer concentration which would have resulted in membranes with larger pores. The presence of $5 \%$ photocatalyst titanium dioxide $\left(\mathrm{TiO}_{2}\right)$ particles in the membrane matrix would have led to an increase in the hydrophobicity of the dope solution and therefore affected the exchanges between the solvent and the non-solvent in the coagulation bath [35]. Additionally, $\mathrm{TiO}_{2}$ particles were evenly well distributed in the membrane, as seen in Figure 2. There was more $\mathrm{TiO}_{2}$ in $\mathrm{M} 2(5 \%)$ than in $\mathrm{M} 1(2.5 \%)$. The size of the nanoparticles of $\mathrm{TiO}_{2}$ appeared to be greater than $21 \mathrm{~nm}$ because the dispersion was not complete by simple agitation. 

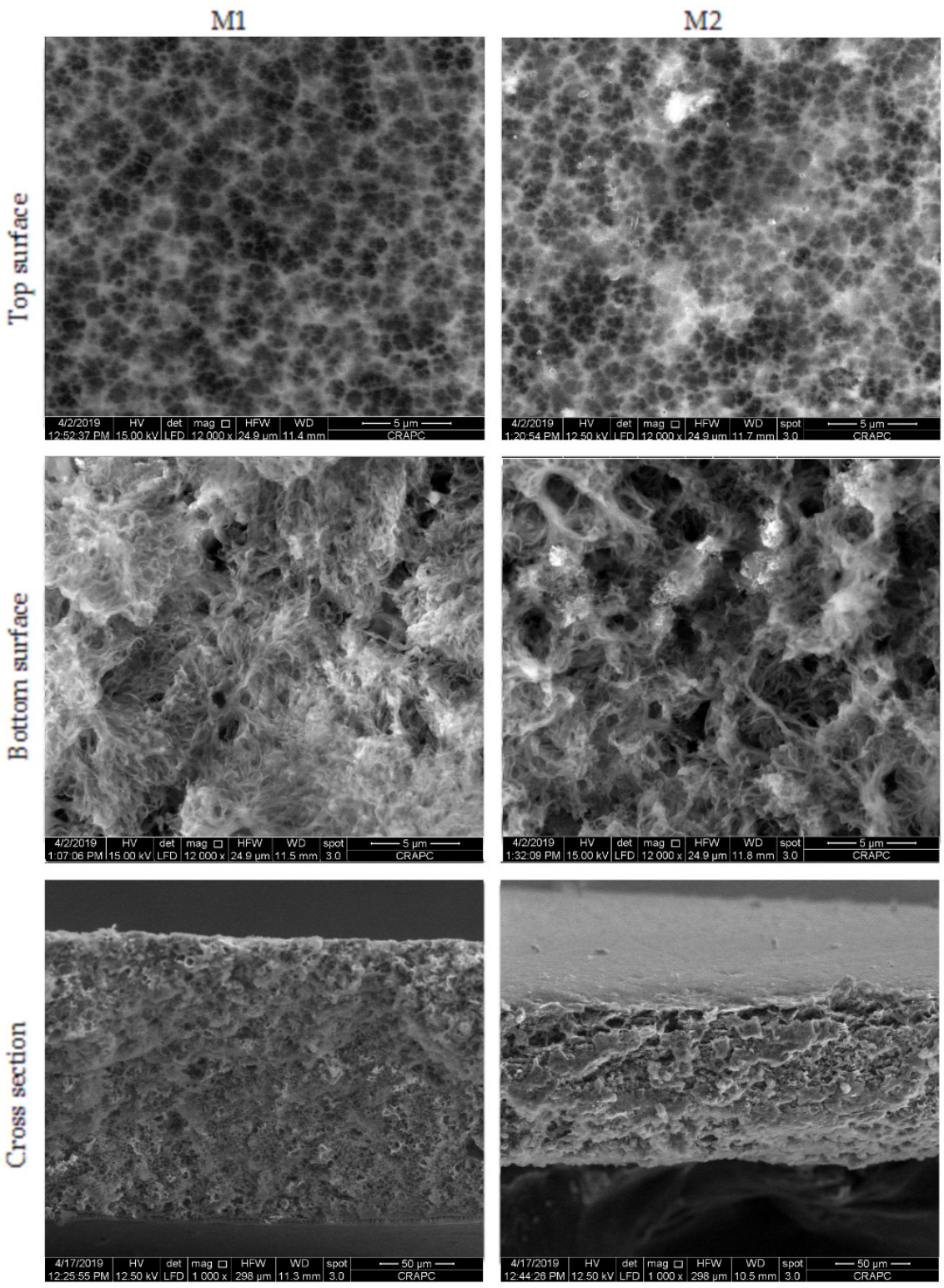

Figure 1. SEM images: top surface, bottom surface, and cross-sections of membranes M1 and M2.

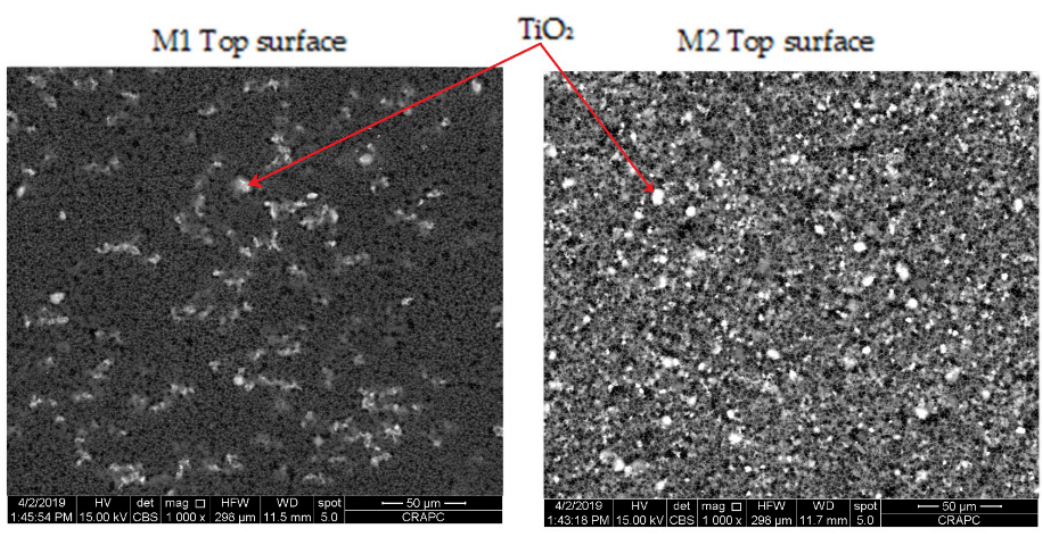

Figure 2. Top surface of membranes M1 and M2 collected on the concentric backscatter (CBS) detector from the FEI company. 


\subsection{Membrane Characterization}

Fabricated membranes were characterized by measuring thickness, porosity, pure water permeability, pore size and contact angle (Table 1). The thickness of M1 was estimated at $0.159 \mathrm{~mm}$ which was greater than M2 at $0.099 \mathrm{~mm}$. Membrane thickness increased concomitantly with an increase in polymer content. For example, the concentrations of PVDF and PMMA was $7 \mathrm{wt} \%$ compared to $6 \mathrm{wt} \%$ in M1 and M2 respectively (Figures 1 and 2). In a related study, Ortiz de Zarate et al. [36] also found that membrane thickness, with a sponge-like structure across the membrane and free of macro voids, increased with a higher polymer content, which presumably delayed separation during phase inversion. Moreover, it was observed that the porosity of M1 decreased (36.44\%) compared to M2 (76.76\%). A less-porous surface was detected when the polymer concentration increased (Figures 1 and 2). The reduction in cavities is presumably a consequence of an increasing polymer concentration. This is a very well documented phenomenon [18,24]. High polymer concentrations, in fact, slow down the precipitation process leading to the formation of a membrane with a lower pore size and therefore a lower porosity.

Table 1. Characteristics of the fabricated membranes.

\begin{tabular}{cccccc}
\hline Membrane & $\begin{array}{c}\text { Membrane Thickness } \\
(\mathbf{m m})\end{array}$ & $\begin{array}{c}\text { Contact Angle } \\
\text { (Degrees) }\end{array}$ & $\begin{array}{c}\text { Pure Water Permeability } \\
\text { (L/hm } \mathbf{~ b a r )}\end{array}$ & $\begin{array}{c}\text { Porosity } \\
\mathbf{( \% )}\end{array}$ & $\begin{array}{c}\text { Pore Size-Average Value } \\
(\mathbf{n m})\end{array}$ \\
\hline M1 & 0.156 & $90 \pm 2.60$ & 158 & 36.44 & 150 \\
M2 & 0.099 & $85 \pm 2.51$ & 226 & 76.76 & 300 \\
\hline
\end{tabular}

All membranes exhibited a hydrophilic nature because of the presence of PVDF and $\mathrm{TiO}_{2}$, which increased the wettability characteristics [32]. This is supported by the low contact angle measurements which gave values of $90^{\circ}$ and $85^{\circ}$ for M1 and M2 respectively.

One of the most important indicators in assessing the structure and morphology of membranes is the pure water permeability (PWP). The PWPs of the fabricated PVDF/PMMA/TiO 2 membranes are illustrated in Figure 3. The membrane prepared with a high polymer content (i.e., M1) led to a low PWP, which is associated with porosity and pore size. For example, for membranes M1 and M2 at a pressure of 1 bar the PWP was 125 and 275 L/h.m ${ }^{2}$.bar respectively. The PWP of membranes decreased with the pressure. For membrane M2 the PWP decreased from 300 to $225 \mathrm{~L} / \mathrm{h} \cdot \mathrm{m}^{2}$.bar as the cross-membrane pressure increased from 0.5 to 1.5 bar. The reason for this could be two-fold. Firstly, for polymeric UF/MF membranes, compaction increases at high pressures which may alter/decrease the pore size, thus decreasing the water passage through the membrane. Secondly, there may have been membrane deformation caused by the metallic support. As the pressure increased, the membrane surface is compressed against the support, and thus exerts an additional resistance to water permeation. These experimental results are similar to those reported in the literature [37].

\subsection{Filtration Tests}

\subsubsection{Impact of Pollutants}

Figure 4 shows the changes in the permeate concentrations of Congo Red, Tartrazine, and Ciprofloxacin as a function of time for the same initial dye concentration. The results showed a good elimination of Congo Red, achieving 99\% removal, and for Tartrazine $81 \%$ elimination despite a molecular weight smaller than the molecular weight cut-off (MWCO) of the membranes. The initial concentration of all pollutant models was $20 \mathrm{mg} / \mathrm{L}$; after $10 \mathrm{~min}$ of filtration, the concentration of Congo Red and Tartrazine in the permeate decreased to $0.5 \mathrm{mg} / \mathrm{L}$; while a concentration of $18 \mathrm{mg} / \mathrm{L}$ was noticed for Ciprofloxacin, even though the differences in molecular weights between the three pollutants were small (i.e., 697, 534, and $331 \mathrm{~g} / \mathrm{mol}$, respectively). The slight increase in Tatrazine concentration in the permeate as a function of time suggests that the separation process for molecules such as Tatrazine also depends on factors other than the MWCO, such as charge. 


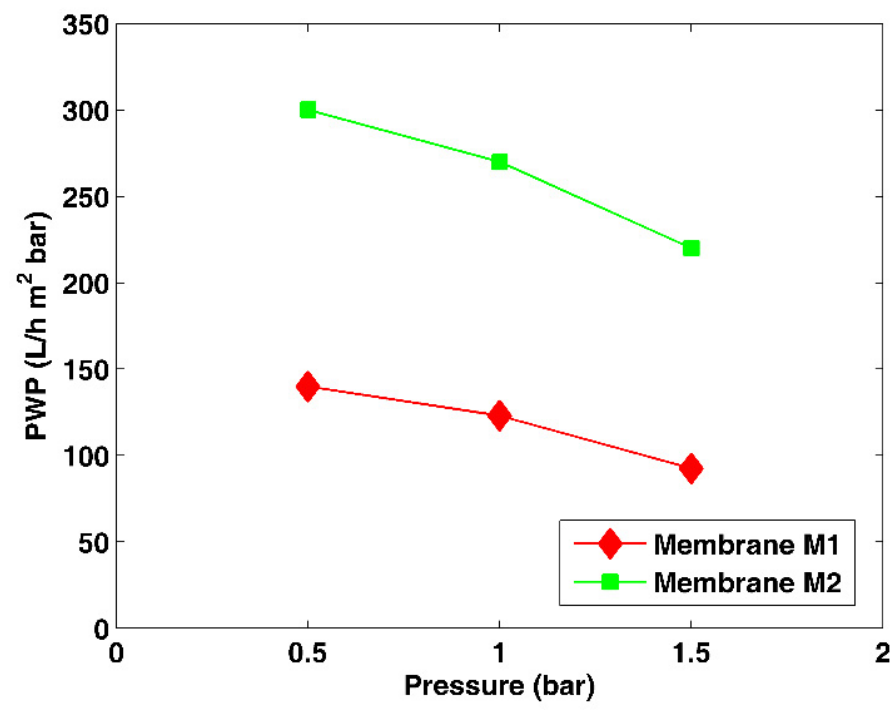

Figure 3. Pure water permeability (PWP) as a function of transmembrane pressure through the membranes M1 and M2.

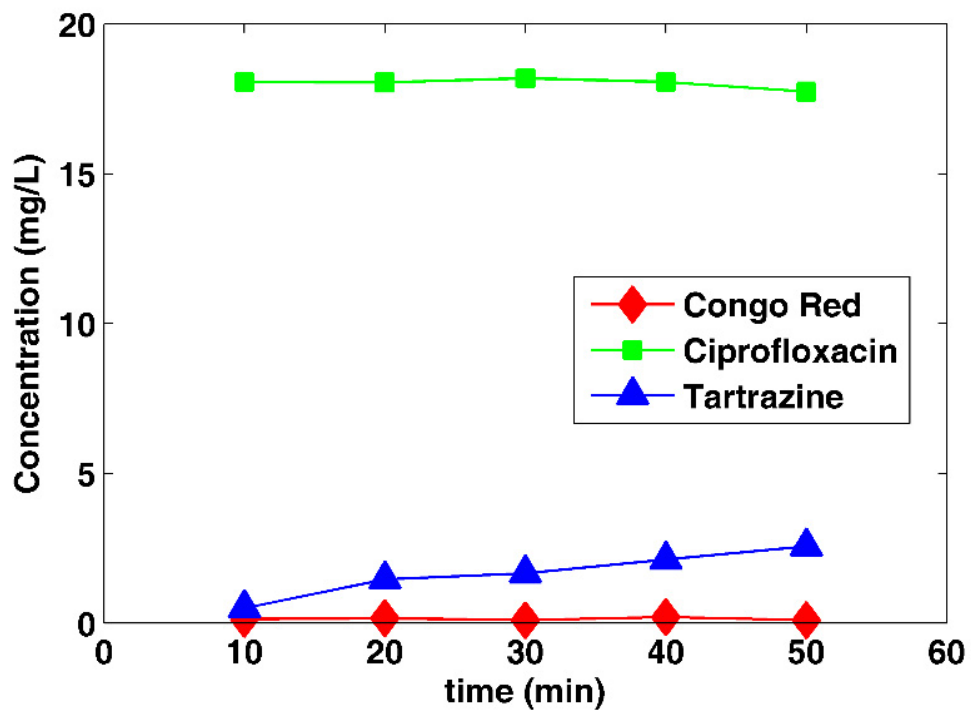

Figure 4. Pollutant concentration in permeate as a function of time for membrane M1.

Recent studies have shown the importance of the charge and shape of the molecules in the ultrafiltration process [38,39]. In Figure 5 it can been seen that Congo Red and Tartrazine have a linear structure with negative charges making it easier for their rejection by membranes with a negative surface charge. On the other hand, the globular structure and neutral charge of Ciprofloxacin reduces its rejection as shown by the higher permeate concentration (Figure 4). These results are similar to those reported by others [38,39].

The elimination rate was higher for the Congo Red (99\%) and for Tartrazine molecule $(81 \%)$ than for the Ciprofloxacin molecule $(15 \%)$. This can be explained with the steric and electrostatic effect between these molecules and the negative charge of the membrane (Figure 5).

Uncharged molecules were able to pass through pores, while small, charged molecules could not pass. For pollutants with low or neutral charge, shape becomes an important factor, with globular being favored over a linear structure. 

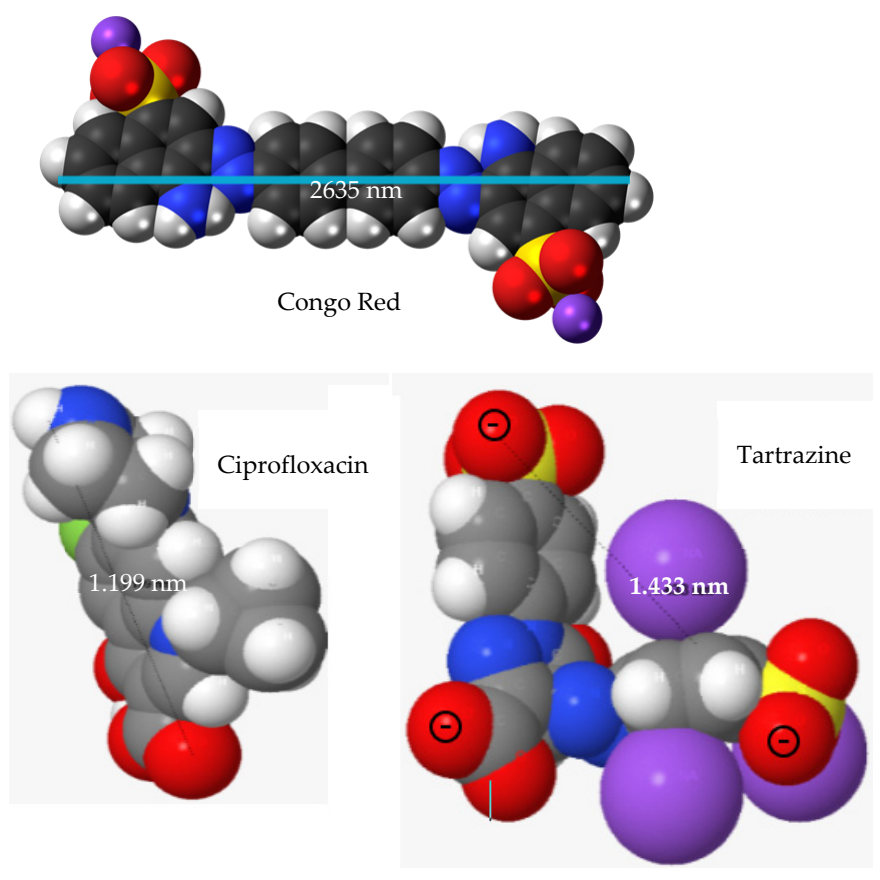

Figure 5. Steric configuration of pollutants models.

\subsubsection{Impact of Operating Conditions}

The concentration of Congo Red in the permeate decreased from $20 \mathrm{mg} / \mathrm{L}$ to $0.2 \mathrm{mg} / \mathrm{L}$ and remained stable throughout the filtration time. The Figure 6 shows that the pressure does not have a visible effect on the membrane retention of the Congo Red.

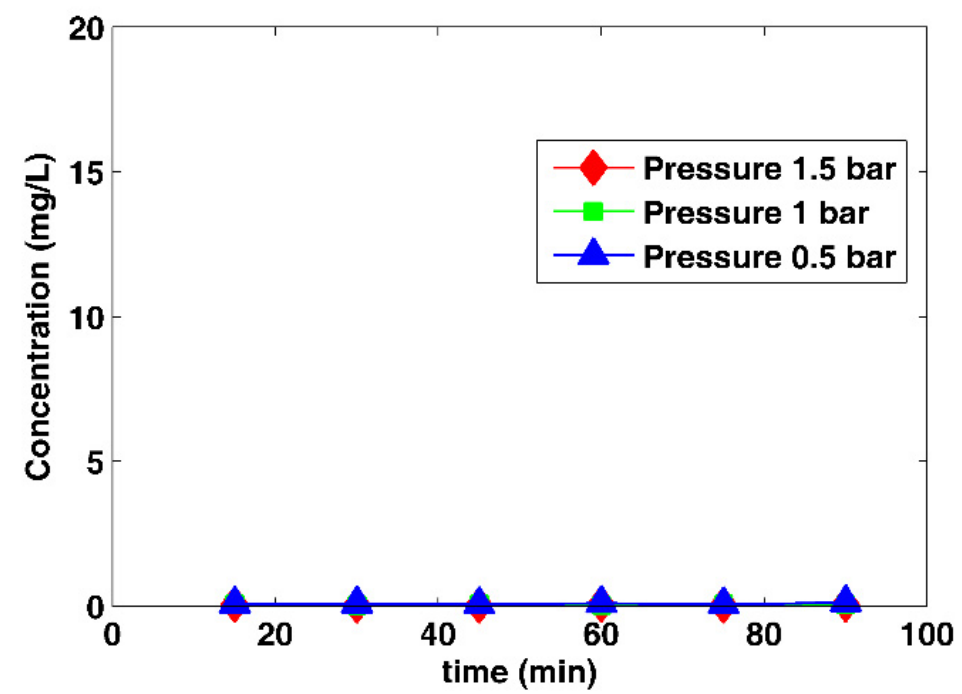

Figure 6. Effect of pressure on permeate concentration of Congo Red solution versus time.

As shown in Figure 7, the pressure applied does not affect the retention rate of Congo Red, unlike the retention rate of Tartrazine, which decreases with pressure. For example, with Tatrazine at $40 \mathrm{mg} / \mathrm{L}$, as the pressure increased from 0.5 to 1.5 bar, retention decreased from $80 \%$ to $38 \%$, respectively. This is presumably due to the smaller size of Tatrazine (slightly lower than MWCO) which allows it to be forced through the pores of the membrane at height pressures. 

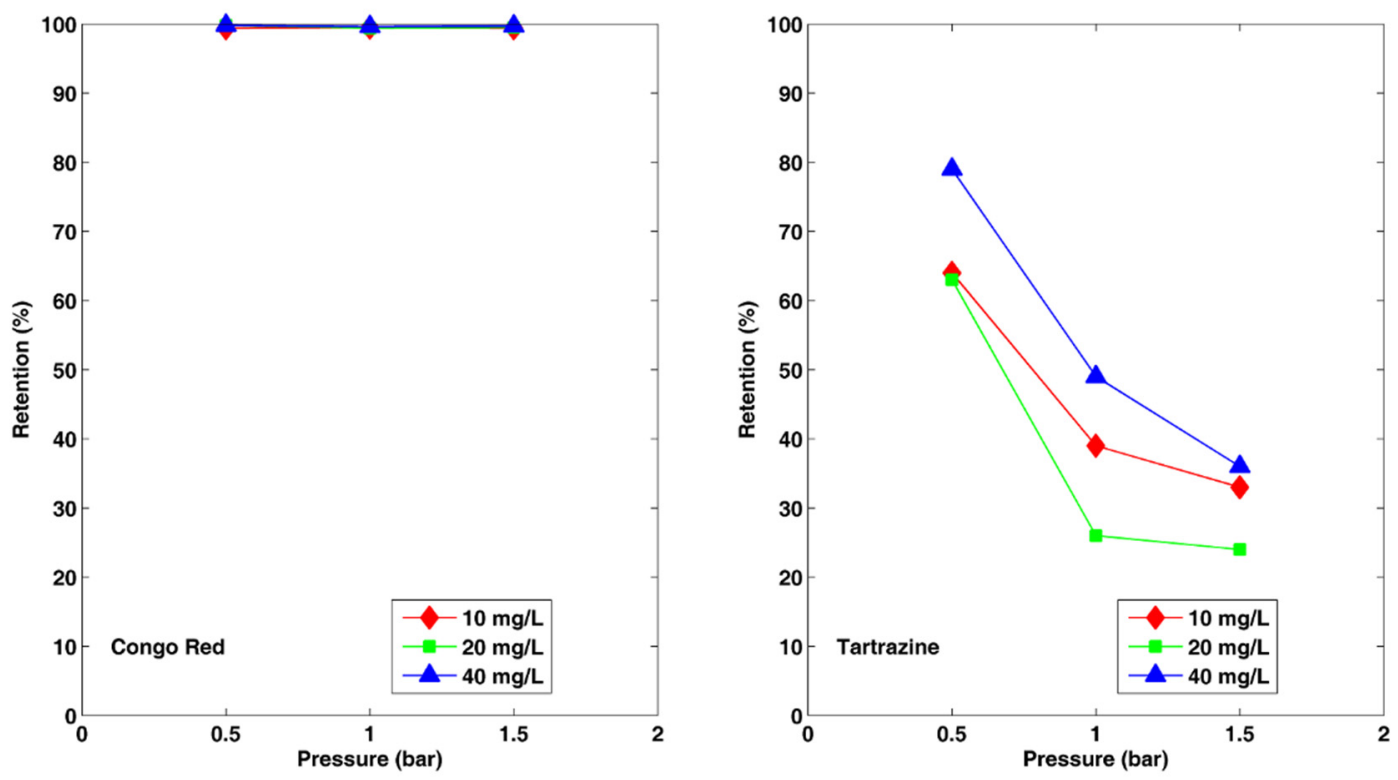

Figure 7. Effect of transmembrane pressure on retention of Congo Red and Tartrazine for the membrane.

In Figure 8, it was observed that the total volume flux linearly increased as the applied pressure increased. On the other hand, it was not greatly affected by the $\mathrm{pH}$. This behavior has also been observed by Bandini et al. [40]. One can speculate that this could be due to the presence of pollutant molecules close to the membrane surface resulting in pore clogging. Consequently, the fluid had difficulty in passing through the pores. In the case of Tatrazine at $20 \mathrm{mg} / \mathrm{L}$ the highest permeate flux $\left(188 \mathrm{~L} / \mathrm{m}^{2} . \mathrm{h}\right)$ was achieved at $1.5 \mathrm{bar}$ and the lowest flux value $\left(88 \mathrm{~L} / \mathrm{m}^{2} . \mathrm{h}\right)$ at 0.5 bar at $90 \mathrm{~min}$ of operation. These results are better than that reported by Waeger et al. [41] who showed that the permeate flux did not increase beyond a 0.5 bar. The improved fluxes in the current study may be due to the charged membrane which helps to repel the pollutant molecules from the surface.
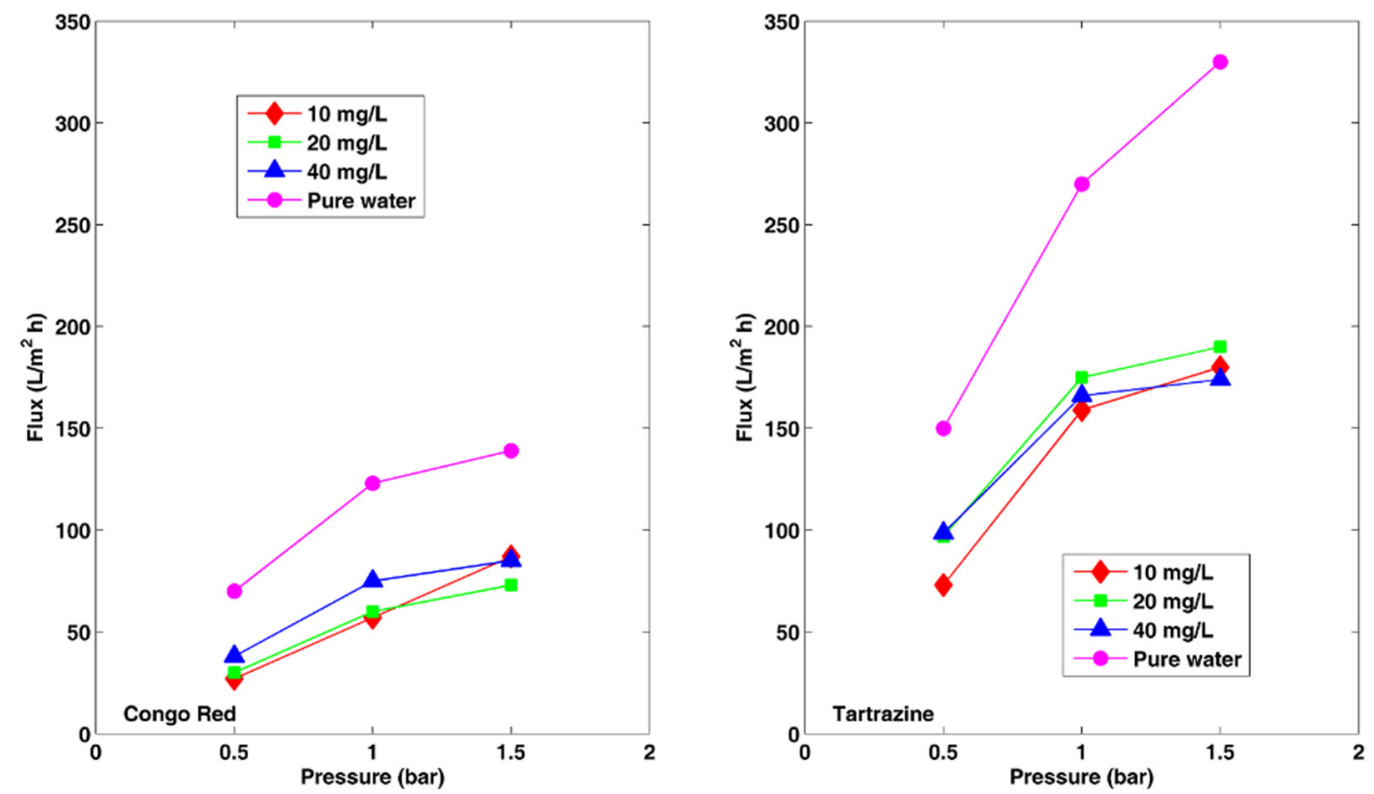

Figure 8. Effect of pressure on permeate flux of pure water and aqueous solutions of Congo Red and Tartrazine through the photocatalytic membrane.

To access the impact of pollutant concentration on the performance of the photocatalytic membrane and on its antifouling properties, a solution of Congo Red was filtered 
at different concentrations. There were no significant differences in pollutant effluent concentrations between low and high feed concentrations of Congo Red (i.e., 10, 20, and $40 \mathrm{mg} / \mathrm{L}$ ) (Figure 9). It can be argued that this was due to the antifouling properties of the negatively charged photocatalytic membrane. Similar results were found by Molinari et al. [42]. Figure 10 shows a difference between Tartrazine and Congo Red. Tartrazine retention increased at higher concentration. For example, from 10 to $20 \mathrm{mg} / \mathrm{L}$, retention was about $65 \%$, while at $40 \mathrm{mg} / \mathrm{L}$, retention increased to $80 \%$. At a higher dye concentration, the dye accumulation on membrane surface probably increased, thus reducing the flux [43].

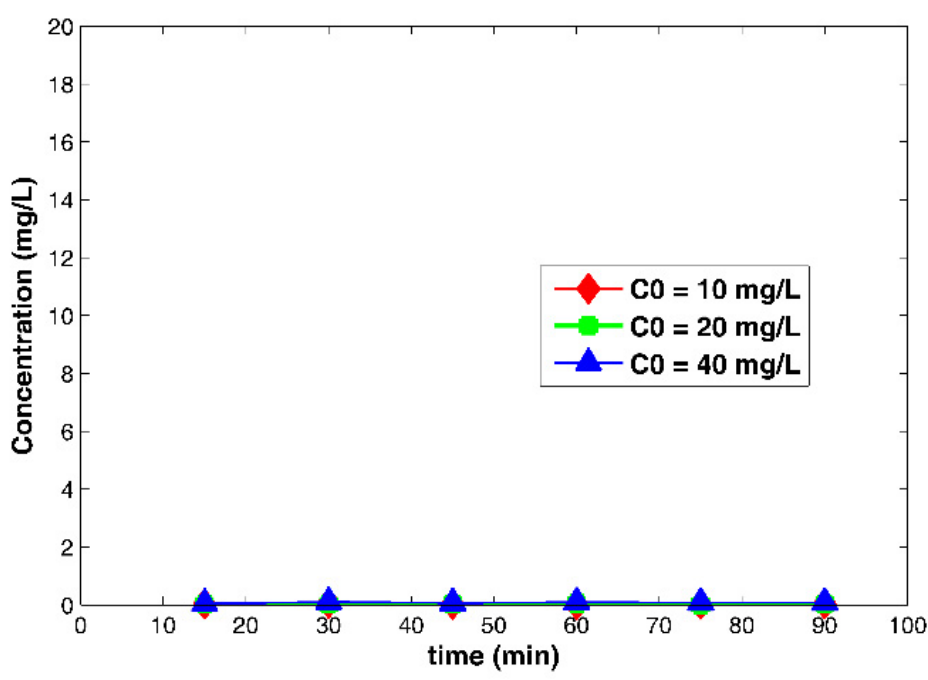

Figure 9. Effect of initial concentration on elimination of Congo Red by filtration using photocatalytic membrane.

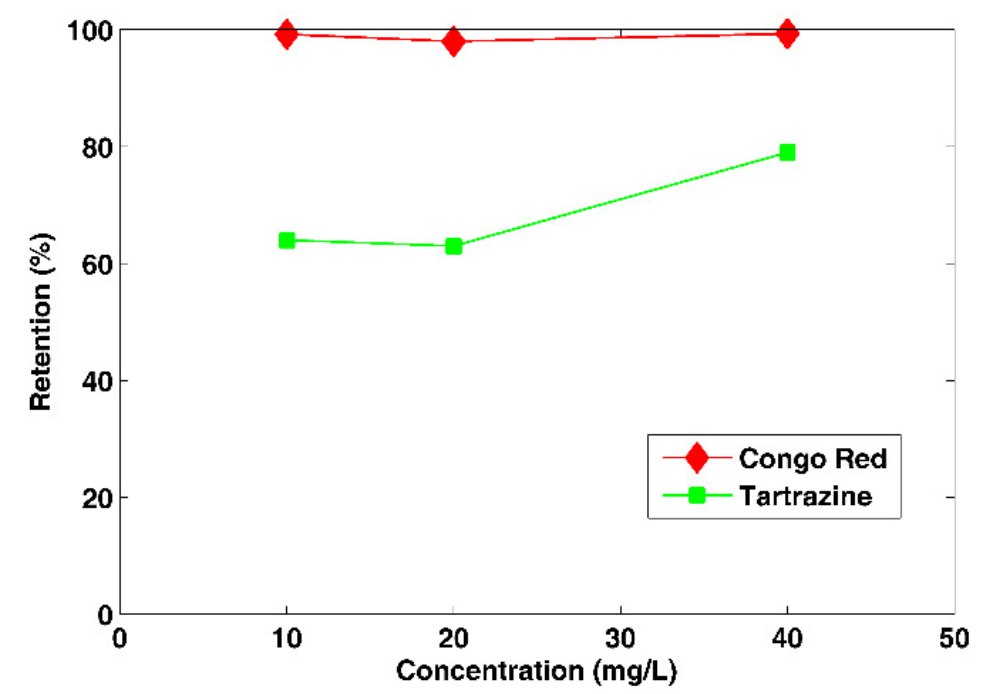

Figure 10. Effect of initial concentration on retention of Congo Red and Tartrazine.

Figure 11 illustrates the changes in Congo Red concentration in the permeate with time using the photocatalytic membrane $\mathrm{M} 1$. There was a significant effect at $\mathrm{pH}=10$ during the first $45 \mathrm{~min}$. However, there was little apparent effect at $\mathrm{pH} 4$ to 7 . All three pollutants behaved the same after $45 \mathrm{~min}$. Thus, the retention of Congo Red by the membrane M1 was not significantly affected by $\mathrm{pH}$ variation after an initial contact time, unlike pollutants of a monovalent and divalent ion nature, where the rejection rate is affected by the $\mathrm{pH}$ value [44]. 


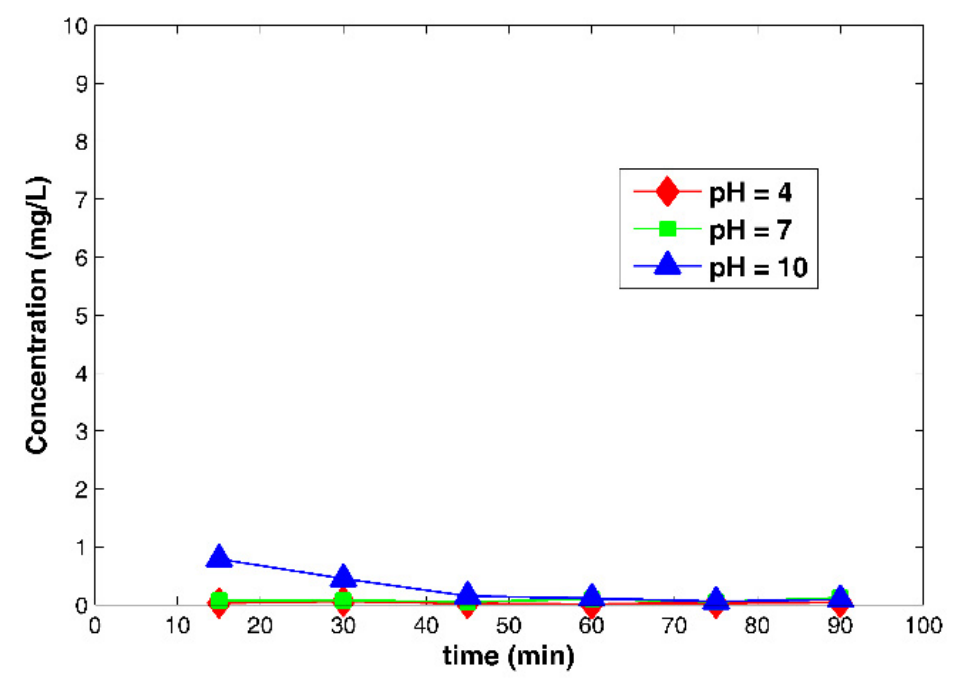

Figure 11. Effect of $\mathrm{pH}$ on concentration of Congo Red in permeate during filtration with photocatalytic membrane $\mathrm{M} 1\left(\mathrm{C}_{0}=10 \mathrm{mg} / \mathrm{L}, \mathrm{P}=0.5\right.$ bar $)$.

\subsubsection{Application of Photocatalytic Membranes for Removal of Bacteria from Wastewater}

In preliminary photocatalytic membrane experiments with wastewater, there was a significant reduction in the bacterial (i.e., Escherichia coli and Streptococcus sp.) concentration due to the treatment. Water taken from a drainage effluent (conductivity $=11.18 \mathrm{~ms} / \mathrm{cm}$ ) gave a turbidity of 9.61 NTU (Nephelometric Turbidity Unit) before filtration and 0.17 NTU in the permeate after filtration using the M1 membrane. The conductivity, however, decreased very little because of filtration. The conductivity before and after filtration was 11.18 and $10.21 \mathrm{~ms} / \mathrm{cm}$, respectively. The lack of change was due presumably to the retention of organic matter and the presence of bivalent or monovalent cations which were retained. However, the pure water permeability (PWP) of the membrane decreased more than half from 140 to $67 \mathrm{~L} / \mathrm{h} \cdot \mathrm{m}^{2}$ and was due likely to the phenomenon of clogging by algae and microorganisms which are resistant to photo catalytic degradation. Removal of algae and microorganisms will require pretreatment.

A rich solution of two bacterial species, Escherichia coli and Streptococcus sp. was filtered through the M1 membrane. After counting on nutrient agar, by the MPN method (Most Probable Number), the results obtained showed a decrease in the two cultures in the permeate to approximately $240 \mathrm{cfu} / \mathrm{mL}$. In addition, it was noted that the microbial populations in the retentate were uncountable.

\section{Experimental}

\subsection{Chemicals}

The polymers polyvinylidene fluoride (PVDF CAS 24937-79-9, Mw = $275 \mathrm{~kg} / \mathrm{mol}$ ) and poly methyl methacrylate (PMMA CAS 9011-14-7, Mw $=350 \mathrm{~kg} / \mathrm{mol}$ ) were supplied by Sigma-Aldrich (82024 Taufkirchen, Germany). Triethyl phosphate (Purity $\geq 99.8 \%$ ) 538728 Sigma Aldrich, Germany) was used as a solvent without further purification. Polyvinylpyrrolidone (PVP10 CAS 9003-39-8 Sigma-Aldrich, 82024 Taufkirchen, Germany, $\mathrm{Mw}=10 \mathrm{~kg} / \mathrm{mol}$ ) and Polyethylene glycol (PEG-200, CAS 25322-68-3 Sigma Aldrich, 82024 Taufkirchen Germany, $\mathrm{Mw}=200 \mathrm{~g} / \mathrm{mol}$ ) were added to the polymeric solution, as pore-forming agents. $\mathrm{TiO}_{2}$ (Aeroxide-Degussa P25) photocatalyst was dispersed in the dope solution. As reported by the supplier, the $\mathrm{TiO}_{2}$ nanoparticles have a primary mean diameter of $21 \mathrm{~nm}$, with a density of $4 \mathrm{~g} / \mathrm{cm}^{3}$ with a predominance of the anatase form. Bi-distilled water was employed as a non-solvent for polymer precipitation.

\subsection{Membrane Fabrication}

Membranes were prepared as described by Benhabiles et al. [45] via the phase inversion technique. A non-solvent induced phase separation (NIPS) was used to fabricate 
flat-sheet membranes using a dope solution containing PMMA, PVDF, PVP, PEG, $\mathrm{TiO}_{2}$ and triethyl phosphate (TEP) as an alternative non-toxic solvent. $\mathrm{TiO}_{2}$ particles are incorporated in the polymer matrix. The dope solution was cast on a glass plate to a predetermined thickness of $350 \mu \mathrm{m}$ using a manual Casting knife (Elcometer 3700 Film Applicator Blade with Tank, Elcometer Instrument $\mathrm{GmbH}$, Aalen, Germany). Two types of membranes were fabricated (Table 2). For example, membranes M1 \& M2 contained 2.5 wt \% and 5 wt \% $\mathrm{TiO}_{2}$ respectively. The produced membranes $(60 \mathrm{~cm} \times 16 \mathrm{~cm})$ are washed three times with water at $60^{\circ} \mathrm{C}$, then dried in open air for $12 \mathrm{~h}$.

Table 2. $\mathrm{TiO}_{2}-\mathrm{PVDF} / \mathrm{PMMA}$ photocatalytic membranes produced by varying casting solution composition.

\begin{tabular}{ccccccc}
\hline Membrane Code & $\mathrm{TiO}_{\mathbf{2}} / \mathbf{w t} \%$ & PVDF/wt $\%$ & PMMA/wt $\%$ & PVP/wt $\%$ & PEG/wt $\%$ & TEP/wt $\%$ \\
\hline M1 & $2.5 \%$ & $7 \%$ & $7 \%$ & $5 \%$ & $5 \%$ & $73.5 \%$ \\
M2 & $5 \%$ & $6 \%$ & $6 \%$ & $5 \%$ & $5 \%$ & $73 \%$ \\
\hline
\end{tabular}

\subsection{Membrane Characterization}

\subsubsection{Membrane Morphology}

Scanning electron microscopy (SEM) was performed to assess the structure, porosity, and thickness of the membrane. A Quanta 250 from the FEI Company was employed for the SEM. Cross sections of the membranes were prepared by fracturing the membranes in liquid nitrogen. Membranes were observed at a magnification ranging from $500 \times$ to $24,000 \times$.

\subsubsection{Membrane Porosity}

Porosity, defined as the pore volume divided by the total volume of the membrane, was calculated by the following equation:

$$
\operatorname{Porosity}(\%)=\frac{\frac{W t_{w}-W t_{d}}{\rho_{k}}}{\frac{W t_{w}-W t_{d}}{\rho_{k}}+\frac{W t_{d}}{\rho_{p}}} \times 100
$$

where $W t_{w}$ is the wet membrane weight, $W t_{d}$ is the dry membrane weight, $\rho_{k}$ is the isopropanol density and $\rho_{p}$ is the polymer density. Each membrane sample was weighed and subsequently submerged in a container filled with isopropanol and stored for $24 \mathrm{~h}$. The test was performed three times and the porosity value was calculated.

\subsubsection{Contact Angle}

The contact angle $\theta$ for the membrane surface was measured by an optical tensiometer (CAM100 Instrument, Nordtest srl, GI, Serravalle Scrivia (AL), Italy) via the drop method. The contact angle determines the wettability and hydrophobicity of the membrane.

\subsubsection{Pure Water Permeability}

A laboratory crossflow cell (DeltaE srl, Italy), operating at $25^{\circ} \mathrm{C}$, was employed to carry out pure water permeability (PWP) experiments. Pure water was passed across the membrane by means of a peristaltic pump (Tuthill Pump Co., Concord, CA, USA). Stability of the permeate flow was achieved before running the permeability tests. PWP was calculated by applying the following equation:

$$
P W P=\frac{Q}{A t \rho}
$$

where $A$ is the membrane area expressed in $\mathrm{m}^{2}$,

$\rho$ is the pressure expressed in bar,

$Q$ is the permeate volume in liters,

and $t$ is the time expressed in hours. 
One of the most important indicators in assessing the structure and morphology of membranes is the pure water permeability (PWP). It was carried out by measuring the flow of permeate at different working pressures in the range $0.5-1.5$ bars.

\subsubsection{Permeate Flux and Retention}

The permeate flux was calculated by dividing the permeate volume by the membrane effective area and a specified time (Equation (3)):

$$
\text { Permeateflux }=\frac{\text { permeatevolumecollected }}{\text { effectivearea } \times \text { time }}
$$

The retention indicates pollutant removal by the membrane and was calculated as follows:

$$
\operatorname{Retention}(\%)=\left(1-\frac{C_{p}}{C_{f}}\right) \times 100
$$

where $C_{p}$ and $C_{f}$ are the concentrations in the permeate and in the feed respectively.

\subsection{Experimental Setup}

Figure 12 represents the experimental setup for membrane performance evaluation by a crossflow filtration cell, also known as tangential flow filtration. All experiments were carried out at room temperature. The system consisted of a reservoir, pump, valves, pressure regulators, and filtration cell with viewport for photocatalytic application designed by DeltaE SRL (Rende (CS) Italy). The peristaltic pump (ESMATEC-IDEX Corporation) was employed to circulate the feed and supply the operating pressure, manometers, and feed tank linked together with polymeric flexible pipes.

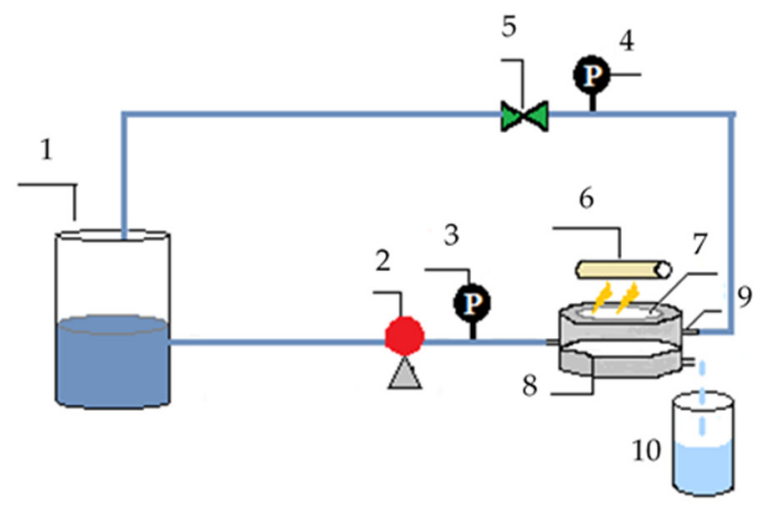
(1) Feed Solution
(2) Pump
(3) Pressure gauge 1
(4) Pressure gauge 2
(5) Control valve
(6) UV lamp
(7) Quartz window
(8) Photocatalytic membrane
(9) Permeate
(10) Retentate

\section{Process parameters}

Feed Volume $1 \mathrm{~L}$ Concentration range: $10-40 \mathrm{mg} / \mathrm{L}$ Flow rate $\approx 2 \mathrm{~L} / \mathrm{min}$ Pressure: $0.5-2$ bars

Figure 12. Schematic of the crossflow system.

The filtration cell was circular with an effective membrane area of $0.0013 \mathrm{~m}^{2}$. The applied feed was formed from dissolving various amounts of model pollutant powder in purified water (i.e., $10 \mathrm{mg} / \mathrm{L}, 20 \mathrm{mg} / \mathrm{L}$ and $40 \mathrm{mg} / \mathrm{L}$ ). The retentate was recirculated to the reservoir and the permeate was collected and measured. The volume of the feed solution was $1 \mathrm{~L}$ for all experiments.

\subsection{Filtration Experiments}

The filtration experiments were carried out using the pilot crossflow system shown in Figure 12 at the Waste Water Treatment and Valorization laboratory (EVER) of the 
Solar Equipment Development Unit (UDES). A flat sheet membrane with $47 \mathrm{~mm}$ diameter $\left(0.0013 \mathrm{~m}^{2}\right.$ effective surface) is supported by a stainless-steel grid integrated in the cell (PMR). Before each filtration test the membrane was washed with purified water for $30 \mathrm{~min}$ in recirculation mode.

The pollutants assessed were chosen according to their physico-chemical properties (e.g., Molecular Weight, pKa, charge) and the size of the pores of the membranes. Three model pollutant compounds were tested, Congo Red (MW = 696.66 Da, $\mathrm{pKa}=4)$, Tartrazine $(\mathrm{MW}=534.3 \mathrm{Da}, \mathrm{pKa}=9.2)$, and Ciprofloxacin $(\mathrm{MW}=331.3 \mathrm{Da}, \mathrm{pKa}=6.09)$. The separation efficiency of the membranes was evaluated by filtration of molecules from different families: Congo Red (697 g/mol); textile dye with the empirical formula $\left(\mathrm{C}_{32} \mathrm{H}_{22} \mathrm{~N}_{6} \mathrm{Na}_{2} \mathrm{O}_{6} \mathrm{~S}_{2}\right)$, Tartrazine $(534 \mathrm{~g} / \mathrm{mol})$ which is a food color with formula $\left(\mathrm{C}_{16} \mathrm{H}_{9} \mathrm{~N}_{4} \mathrm{Na}_{3} \mathrm{O}_{9} \mathrm{~S}_{2}\right)$, and a pharmaceutical product Ciprofloxacin $(331 \mathrm{~g} / \mathrm{mol})$ with the molecular formula $\left(\mathrm{C}_{17} \mathrm{H}_{18} \mathrm{FN}_{3} \mathrm{O}_{3}\right)$.

A volume of $1 \mathrm{~L}$ at $20 \mathrm{mg} / \mathrm{L}$ of each pollutant was filtered through the membrane M1 under a pressure of 0.5 bar. The filtration tests were carried out at room temperature under a transmembrane pressure varying from 0.5 bar to 1.5 bar, with recirculation of the retentate and permeation to the feed tank.

The concentration of pollutants in the permeate and the retentate were quantitatively determined using a spectrophotometer Shimadzu UV-VIS 18000, at a wavelength of $497 \mathrm{~nm}$ for Cong Red, $427 \mathrm{~nm}$ for Tatrazine, and $273 \mathrm{~nm}$ for Ciprofloxacin. The determined concentrations were used for calculation of the retention rate. The impact of operating conditions: $\mathrm{pH}$, pressure, and pollutant concentration in the feed were studied. The evolution of concentration in the permeate and retentate solution was assessed by spectroscopy UV for the chemical pollutants. The flux and the retention values for each pollutant was measured and compared.

\subsection{Application of Photocatalytic Membranes for Bacteria Removal from Wastewater}

The use of filtration with a photocatalytic membrane to eliminate bacteria (Escherichia coli and Streptococcus sp.) present in a wastewater solution containing a mixture of the two strains was assessed. The conductivity of water taken from a drainage effluent before and after filtration by the M1 membrane was evaluated. A culture was performed on nutritive agar for the retentate and for the permeate. These results were analyzed to determine how well the photocatalytic membrane retained bacteria.

\section{Conclusions}

The resulting $\mathrm{TiO}_{2}-\mathrm{PVDF} / \mathrm{PMMA}$ nano-composites flat sheet membranes had a high permeability and porosity that could retain organic molecules such as Congo Red (MW $696.66 \mathrm{~g} / \mathrm{mol}$ ), and thus is an excellent candidate for use in the treatment of wastewater from the pharmaceutical industry.

The results revealed an excellent elimination of Congo Red with 99\% removal and $81 \%$ for Tartrazine. However, a decrease of only $15 \%$ was observed for Ciprofloxacin. This behavior suggests that the separation process depends on factors other than the molecular weight cut-off of the membrane (MWCO), such as charge. Results suggest that negative charge on the hydrophilic membrane plays a significant role in the rejection process. In addition to filtration performance, the $\mathrm{TiO}_{2}$ in the polymer matrix has antifouling properties.

In experiments with wastewater, there was a significant reduction in the bacterial (Escherichia coli and Streptococcus sp.) concentrationobserved.

Operating pressures $(0.5-1.5$ bar $)$ do not have a significant effect on the retention of pollutants. In all cases, permeate flux was increased by raising the operating pressure and decreased by increasing the organic concentration. Under similar operating conditions, $\mathrm{pH}$ showed a variable influence on the retention of the model pollutant molecules with no significant influence observed for Tatrazine, Ciprofloxacin, and Red Congo.

Additional studies are still needed to take advantage of photocatalytic membrane potential and develop their anti-clogging performance. 
Author Contributions: Conceptualization, K.B.E., O.B. and H.M.; Methodology, O.B. and H.M.; Validation, K.B.E., O.B., S.B. and Z.B.; Formal Analysis, O.B. and K.B.E.; Investigation, K.B.E., O.B.; Data Curation, M.G. and H.M.; All authors have read and agreed to the published version of the manuscript.

Funding: This research received no external funding.

Conflicts of Interest: The authors declare no conflict of interest.

\section{References}

1. Rout, P.R.; Zhang, T.C.; Bhunia, P.; Surampalli, R.Y. Treatment technologies for emerging contaminants in wastewater treatment plants: A review. Sci. Total Environ. 2020, 753, 141990. [CrossRef] [PubMed]

2. Margot, J.; Rossi, L.; Barry, D.A.; Holliger, C. A review of the fate of micropollutants in wastewater treatment plants. Wiley Interdiscip. Rev. Water 2015, 2, 457-487. [CrossRef]

3. Rodriguez-Narvaez, O.M.; Peralta-Hernandez, J.M.; Goonetilleke, A.; Bandala, E.R. Treatment technologies for emerging contaminants in water: A review. Chem. Eng. J. 2017, 323, 361-380. [CrossRef]

4. Deng, Y.; Zhao, R. Advanced oxidation processes (AOPs) in wastewater treatment. Curr. Pollut. Rep. 2015, 1, 167-176. [CrossRef]

5. Malato, S.; Fernández-Ibáñez, P.; Maldonado, M.I.; Blanco, J.; Gernjak, W. Decontamination and disinfection of water by solar photocatalysis: Recent overview and trends. Catal. Today 2009, 147, 1-59. [CrossRef]

6. Al-Dawery, S.K. Photo-catalyst degradation of tartrazine compound in wastewater using $\mathrm{TiO}_{2}$ and UV light. J. Eng. Sci. Technol. 2013, 8, 683-691.

7. da Silva, S.W.; Klauck, C.R.; Siqueira, M.A.; Bernardes, A.M. Degradation of the commercial surfactant nonylphenol ethoxylate by advanced oxidation processes. J. Hazard. Mater. 2015, 282, 241-248. [CrossRef]

8. Mierzwa, J.C.; Rodrigues, R.; Teixeira, A.C.S.C.; Ameta, I.S.C.; Ameta, R. Advanced Oxidation Processes for Wastewater Treatment: Emerging Green Chemical Technology; Academic Press: Cambridge, MA, USA, 2018; pp. 13-48.

9. Amor, C.; Marchão, L.; Lucas, M.S.; Peres, J.A. Application of advanced oxidation processes for the treatment of recalcitrant agro-industrial wastewater: A review. Water 2019, 11, 205. [CrossRef]

10. Fernandes, A.; Makoś, P.; Wang, Z.; Boczkaj, G. Synergistic effect of $\mathrm{TiO}_{2}$ photocatalytic advanced oxidation processes in the treatment of refinery effluents. Chem. Eng. J. 2020, 391, 123488. [CrossRef]

11. Norman, N.; Anthony, L.; Fane, G.; Ho, W.S.W.; Matsuura, T. Advanced Membrane Technology and Applications; John Wiley \& Sons, Inc.: Hoboken, NJ, USA, 2008.

12. Goh, P.S.; Wong, T.W.; Lim, J.W.; Ismail, A.F.; Hilal, N. Chapter 9-Innovative and sustainable membrane technology for wastewater treatment and desalination application. Innov. Strateg. Environ. Sci. 2020, 291-319.

13. Khalil, A.M.; Schäfer, A.I. Cross-linked $\beta$-cyclodextrin nanofiber composite membrane for steroid hormone micropollutant removal from water. J. Membr. Sci. 2021, 618, 118228. [CrossRef]

14. Cseri, L.; Topuz, F.; Abdulhamid, M.A.; Alammar, A.; Budd, P.M.; Szekely, G. Electrospun Adsorptive Nanofibrous Membranes from Ion Exchange Polymers to Snare Textile Dyes from Wastewater. Adv. Mater. Technol. 2021, 2000955. [CrossRef]

15. Ahdab, Y.D.; Rehman, D. Brackish water desalination for greenhouses: Improving groundwater quality for irrigation using monovalent selective electrodialysis reversal. J. Membr. Sci. 2020, 610, 118072. [CrossRef]

16. Abdulaziz, A.; Sang-Hee, P.; Izwaharyanie, I.; Deepak, A.; Tibor, H.; Ludovic, F.D.; Hong Ngee, L.; Gyorgy, S. Architecting neonicotinoid-scavenging nanocomposite hydrogels for environmental remediation. Appl. Mater. Today 2020, $21,100878$.

17. Sun, C.; Zhang, N.; Li, F.; Ke, G.; Song, L.; Liu, X.; Liang, S. Quantitative analysis of membrane fouling mechanisms involved in microfiltration of humic acid-protein mixtures at different solution conditions. Water 2018, 10, 1306. [CrossRef]

18. Galiano, F.; Figoli, A.; Deowan, S.A.; Johnson, D.; Altinkaya, S.A.; Veltri, L.; De Luca, G.; Mancuso, R.; Hilal, N.; Gabriele, B.; et al. A step forward to a more efficient wastewater treatment by membrane surface modification via polymerizable bicontinuous microemulsion. J. Membr. Sci. 2015, 482, 103-114. [CrossRef]

19. Molinari, R.; Lavorato, C.; Argurio, P. Recent progress of photocatalytic membrane reactors in water treatment and in synthesis of organic compounds. A review. Catal. Today 2017, 281, 144-164. [CrossRef]

20. Benhabiles, O.; Mahmoudi, H.; Lounici, H.; Goosen, M.F.A. Effectiveness of a photocatalytic organic membrane for solar degradation of methylene blue pollutant. Desalin. Water Treat. 2016, 57, 14067-14076. [CrossRef]

21. Choi, H.; Stathatos, E.; Dionysiou, D.D. Photocatalytic $\mathrm{TiO}_{2}$ films and membranes for the development of efficient wastewater treatment and reuse systems. Desalination 2007, 202, 199-206. [CrossRef]

22. Figoli, A.; Ursino, C.; Galiano, F.; Di Nicolò, E.D.; Campanelli, P.; Carnevale, M.C.; Criscuoli, A. Innovative hydrophobic coating of perfluoropolyether (PFPE) on commercial hydrophilic membranes for DCMD application. J. Membr. Sci. 2017, 522, 192-201. [CrossRef]

23. Hsu, C.H.; Venault, A.; Huang, Y.T.; Wu, B.W.; Chou, C.J.; Ishihara, K.; Chang, Y. Toward antibiofouling PVDF membranes Langmuir 2019, 35, 6782-6792. [CrossRef]

24. Romanos, G.E.; Athanasekou, C.P.; Likodimos, V.; Aloupogiannis, P.; Falaras, P. Hybrid Ultrafiltration/Photocatalytic Membranes for Efficient Water Treatment. Ind. Eng. Chem. 2013, 52, 13938-13947. [CrossRef] 
25. Li, X.; Lu, X. Morphology of polyvinylidene fluoride and its blend in thermally induced phase separation process. J. Appl. Polym. Sci. 2006, 101, 2944-2952. [CrossRef]

26. Gnanou, Y.; Fontanille, M. Organic and Physical Chemistry of Polymers; Wiley Blackwell: Hoboken, NJ, USA, 2008.

27. Matindi, C.N.; Hu, M.; Kadanyo, S.; Ly, Q.V.; Gumbi, N.N.; Dlamini, D.S.; Li, J.; Hu, Y.; Cui, Z.; Li, J. Tailoring the morphology of polyethersulfone/sulfonated polysulfone ultrafiltration membranes for highly efficient separation of oil-in-water emulsions using TiO2 nanoparticles. J. Membr. Sci. 2021, 620, 118868. [CrossRef]

28. Yu, J.; Zhang, Y.; Chen, J.; Cui, L.; Jing, W. Solvothermal-induced assembly of 2D-2D rGO-TiO2 nanocomposite for the construction of nanochannel membrane. J. Membr. Sci. 2020, 600, 117870. [CrossRef]

29. Figoli, A.; Simone, S.; Drioli, E.; Hilal, I.N.; Ismail, A.F.; Wright, C. Membrane Fabrication; Taylor \& Francis Group: Boca Raton, FL, USA, 2015; pp. 1-42.

30. Marino, T.; Blefari, S.; di Nicolò, E.; Figoli, A. A more sustainable membrane preparation using triethyl phosphate as solvent. Green Process. Synth. 2017, 6, 295-300. [CrossRef]

31. Mozia, S.; Darowna, D.; Przepiórski, J.; Morawski, A.W. Evaluation of performance of hybrid photolysis-DCMD and photocatalysis-DCMD systems utilizing UV-C radiation for removal of diclofenac sodium salt from water. Pol. J. Chem. Technol. 2013, 15, 51-60. [CrossRef]

32. Said, M.; Nasir, S.; Priadi, D.P. The Effect of Pressure and Time Operation of Gasing River Water Treasure on Pollutant Concentration by Using Ceramic Membrane Separation. Sriwij. J. Environ. 2018, 3, 47-54. [CrossRef]

33. Marino, T.; Russo, F.; Figoli, A. The Formation of polyvinylidene fluoride membranes with tailored properties via vapour/nonsolvent induced phase separation. Membranes 2018, 8, 71. [CrossRef] [PubMed]

34. Wang, L.; Yong, W.F.; Yu, L.E.; Chung, T. Design of high efficiency PVDF-PEG hollow fibers for air filtration of ultrafine particles. J. Membr. Sci. 2017, 535, 342-349. [CrossRef]

35. Drelich, J.; Chibowsk, E. Superhydrophilic and superwetting surfaces: Definition and mechanisms of control. Langmuir 2010, 26, 18621-18623. [CrossRef]

36. de Zárate, J.M.O.; Peña, L.; Mengual, J.I. Characterization of membrane distillation membranes prepared by phase inversion. Desalination 1995, 100, 139-148. [CrossRef]

37. Kim, Y.C.; Elimelech, M. Adverse impact of feed channel spacers on the performance of pressure retarded osmosis. Environ. Sci. Technol. 2012, 46, 4673-4681. [CrossRef]

38. Arsuaga, J.M.; Sotto, A.; López-Muñoz, M.J.; Braeken, L. Influence of type and position of functional groups of phenolic compounds on NF/RO performance. J. Membr. Sci. 2011, 372, 380-386. [CrossRef]

39. Revchuk, A.D.; Suffet, I.N. Ultrafiltration separation of aquatic natural organic matter: Chemical probes for quality assurance. Water Res. 2009, 43, 3685-3692. [CrossRef] [PubMed]

40. Bandini, S.; Drei, J.; Vezzani, D. The role of $\mathrm{pH}$ and concentration on the ion rejection in polyamide nanofiltration membranes. J. Membr. Sci. 2005, 264, 65-74. [CrossRef]

41. Waeger, F.; Delhaye, T.; Fuchs, W. The use of ceramic microfiltration and ultrafiltration membranes for particle removal from anaerobic digester effluents. Sep. Purif. Technol. 2010, 73, 271-278. [CrossRef]

42. Molinari, R.; Pirillo, F.; Falco, M.; Loddo, V.; Palmisano, L. Photocatalytic degradation of dyes by using a membrane reactor. Chem. Eng. Process. 2004, 43, 1103-1114. [CrossRef]

43. Koyuncu, I. Reactive dye removal in dye/salt mixtures by nanofiltration membranes containing vinylsulphone dyes: Effect of feed concentration and cross flow velocity. Desalination 2002, 143, 243-253. [CrossRef]

44. Qin, J.-J.; Oo, M.H.; Lee, H.; Coniglio, B. Effect of feed $\mathrm{pH}$ on permeate $\mathrm{pH}$ and ion rejection under acidic conditions in NF process. J. Membr. Sci. 2004, 232, 153-159. [CrossRef]

45. Benhabiles, O.; Galiano, F.; Marino, T.; Mahmoudi, H.; Lounici, H.; Figoli, A. Preparation and characterization of TiO2PVDF/PMMA blend membranes using an alternative non-toxic solvent for UF/MF and photocatalytic application. Molecules 2019, 24, 724. [CrossRef] [PubMed] 